\title{
Residual antibacterial activity of a new modified sodium hypochlorite-based endodontic irrigation solution
}

\author{
Zahed Mohammadi ${ }^{1}$, Ali Mombeinipour ${ }^{2}$, Luciano Giardino ${ }^{3}$, Shahriar Shahriari ${ }^{4}$
}

\author{
${ }^{1}$ Assistant Professor and Head, Department of Endodontics, Hamedan University of Medical Sciences, Hamedan, Iran \& Iranian \\ Center for Endodontic Research (ICER), Tehran, Iran \\ ${ }^{2}$ Post-graduate student, Department of Endodontics, Hamedan University of Medical Sciences, Hamedan, Iran \\ ${ }^{3}$ Department of Periodontology, Dental, School, University of Brescia, Italy \\ ${ }^{4}$ Associate Professor, Department of Endodontics, Hamedan University of Medical Sciences, Hamedan, Iran
}

Correspondence:

Department of Endodontics,

Hamedan University of Medical Sciences,

Pajoohesh Cross Road,

Hamedan, Iran

mohammadi_zahed@yahoo.com

\begin{abstract}
Mohammadi Z, Mombeinipour A, Giardino L, Shahriari S. Residual antibacterial activity of a new modified sodium hypochlorite-based endodontic irrigation solution. Med Oral Patol Oral Cir Bucal. 2011 Jul 1;16 (4):e588-92.

http://www.medicinaoral.com/medoralfree01/v16i4/medoralv16i4p588.pdf
\end{abstract}

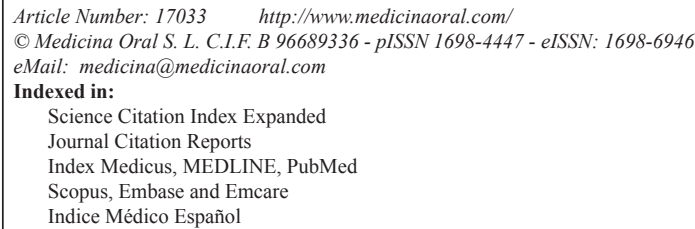

\begin{abstract}
Objective: In this in vitro study the antibacterial substantivity of a new sodium hypochlorite-based root canal irrigant (Hypoclean) in bovine root dentin was investigated.

Study Design: Ninety dentin tubes prepared from bovine incisor teeth were used. After contamination for 14 days with Enterococcus faecalis, the specimens were divided into five groups as follows: Hypoclean; Tetraclean; $5.25 \%$ sodium hypochlorite $(\mathrm{NaOCl})$; infected dentin tubes (positive control); and sterile dentin tubes (negative control). Dentin chips were collected with round burs into tryptic soy broth and after culturing, the number of colony-forming units (CFU) was counted.

Results: The number of CFU was minimum in the first cultures in all experimental groups, and the results obtained were significantly different from each other at any time period $(\mathrm{P}<0.05)$. At all five experimental periods, the Tetraclean group showed the most effective antibacterial action $(\mathrm{P}<0.05)$. Regular $5.25 \% \mathrm{NaOCl}$ group showed the worst result at all periods. Hypoclean group demonstrated no bacterial growth after treatment. In each group, the number of CFU increased significantly by time-lapse $(\mathrm{P}<0.05)$.

Conclusion: The residual antibacterial activity of Tetraclean was significantly greater than Hypoclean and 5.25\% $\mathrm{NaOCl}$.
\end{abstract}

Key words: Enterococcus faecalis, Hypoclean, residual antibacterial activity, sodium hypochlorite, Tetraclean. 


\section{Introduction}

The major contribution of microorganisms in the initiation and perpetuation of pulpal and periapical diseases has clearly been demonstrated in animal models and human studies (1-3). The elimination of microorganisms from infected root canal systems is a complicated task involving the use of various instrumentation techniques, irrigation regimens and intra-canal medicaments. Mechanical instrumentation alone does not result in a bacteria-free root canal system and when the complex anatomy of the root canal system (4) is considered, this is not surprising. Furthermore, ex vivo and clinical evidence has revealed that mechanical instrumentation leaves significant portions of the root canal walls untouched (5) and complete elimination of bacteria by instrumentation alone is unlikely to occur (6). Therefore, some form of irrigation and disinfection is necessary to remove residual tissue and to kill microorganisms. In cases with necrotic pulps as well as in retreatment cases, treatment should be performed in two visits, which is more time-consuming than one-visit treatment (7). In addition, some studies have suggested that calcium hydroxide is ineffective against Enterococcus faecalis (8). To overcome the aforementioned problems, an alternative protocol is to use antimicrobial agents that exhibit substantivity, that is, agents that can have a therapeutic effect for a prolonged period.

Sodium hypochlorite $(\mathrm{NaOCl})$ is the most commonly used root canal irrigation solution. Despite its excellent tissue-dissolving and antimicrobial abilities $(9,10)$, $\mathrm{NaOCl}$ possesses some drawbacks. One of its major drawbacks of $\mathrm{NaOCl}$ is its toxicity. Navarro-Escobar et al. (11) showed the toxicity of $2.5 \% \mathrm{NaOCl}$ on the cell cultures of 3T3L1 fibroblasts. Another major drawback is its high surface tension, which limits it penetration into canal irregularities and the depth of dentinal tubules. Adding a surfactant to $\mathrm{NaOCl}$ can resolve this problem. Recently, a new modified sodium hypochlorite solution has been introduced by Luciano Giardino in Italy. New modified sodium hypochlorite solution (Hypoclean) is a detergents-based endodontic irrigant composed of $5.25 \%$ sodium hypochlorite and two detergents. Like chlorhexidine (CHX) (12), tetracyclines readily attach to dentin and are subsequently released without losing their antibacterial activity (13). Tetraclean (Ogna Laboratori Farmaceutici, Muggiò, Italy), like MTAD (a mixture of a tetracycline isomer, an acid, and a detergent), is a tetracycline-based endodontic irrigant composed of an antibiotic an acid and a detergent (14). However, the concentration of the antibiotic, doxycycline $(50 \mathrm{mg} \mathrm{mL}-1)$ and the type of detergent (polypropylene glycol) differ from those of MTAD (14). The aim of this study was to compare the antimicrobial substantivity of Hypoclean, Tetraclean and $\mathrm{NaOCl}$ against E. faecalis in bovine root dentin in vitro.

\section{Material and Methods}

The method of this study was based on the procedure previously described by Haapasalo and Orstavik (8). Intact bovine central incisor teeth were used for this study.

The teeth were kept in $0.5 \% \mathrm{NaOCl}$ solution for up to 7 days. The clinical crown and apical third were removed from each tooth with a rotary diamond saw at 1000 rpm (Isomet Plus precision saw, Buehler, IL, USA) under water-cooling. Cementum was removed by using polish paper (Ecomet 3, variable-speed grinder-polisher, Buehler, IL, USA), which resulted in a centre-holed piece of root dentin with a 6-mm outer diameter (Fig. 1). The remained piece of each tooth was then cut into 4-mm thick slices with a diamond saw as above. The canals of the 4-mm blocks were enlarged (standardized) with an ISO 023 slow speed round bur. In order to prevent dehydration, all teeth and dentin slices were preserved in vials containing tap water during the procedures. Each dentin block $(\mathrm{n}=90)$ was individually treated with $5.25 \% \mathrm{NaOCl}$ and $17 \%$ ethylene diamine tetraacetic acid (EDTA) (with $\mathrm{pH}$ 7.2) to remove the smear layer. The specimens were then placed in Brain Heart Infusion (BHI) broth (Oxoid, Basingstoke, UK) and autoclaved. To monitor the efficacy of the sterilization they were then kept in an incubator at $37^{\circ} \mathrm{C}$ for $24 \mathrm{~h}$. A total of 80 specimens were randomly divided into five groups as follows: Group 1 (20 specimens): Tetraclean; Group 2 (20 specimens): modified NaOCl; Group 3 (20 specimens): 5.25\% NaOCl; Group 4 (10 specimens): positive control (infected dentin tubes); and Group 5 (10 specimens): negative control (sterile dentin tubes). Isolated 24-h colonies of pure cultures of E. faecalis (ATCC 29212) were suspended in $5 \mathrm{ml}$ of BHI. The bottles containing each specimen in Groups 1, 2, 3 and 4 were opened under laminar flow. Two milliliters of ster-

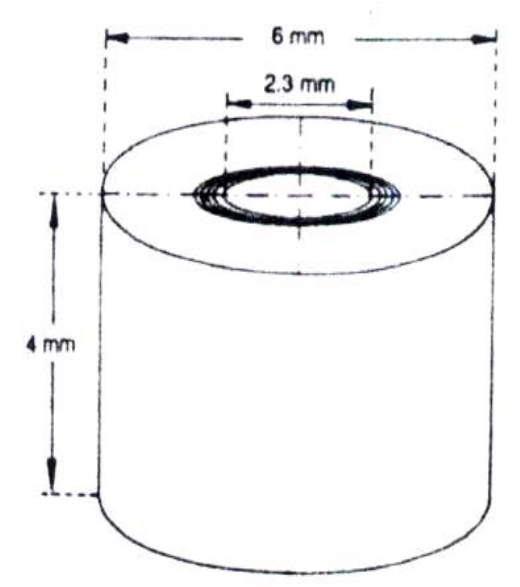

Fig. 1. Schematic view of used dentin tubes (adopted from Mohammadi and Shahriari (12). 
ile BHI was removed with sterile pipettes and replaced with $2 \mathrm{ml}$ of bacterial inoculum. The bottles were closed and kept at $37^{\circ} \mathrm{C}$ for 14 days, with the replacement of 1 $\mathrm{ml}$ of contaminated BHI for $1 \mathrm{ml}$ of freshly prepared BHI every 2 days, to avoid medium saturation. After the contamination period, each specimen was removed from its bottle under aseptic conditions, and the canal was irrigated with $5 \mathrm{ml}$ of sterile saline and dried with sterile paper points. In order to prevent contact of the medicament with the external surface, the outer surface of the specimens was covered with two layers of nail varnish. Thereafter, using decontaminated sticky wax, specimens were fixed at the bottom of wells of 24-well cell culture plates which also obliterated the apical surface of the root canal. Finally, the irrigating solutions were inserted into the canal lumen with sterile 3-ml plastic syringes and 27-gauge needles until the dentin tubes were totally filled. Solutions were removed using sterile paper points ten minutes after placement into the lumen. The specimens were then incubated at $37^{\circ} \mathrm{C}$ for 28 days to maintain humidity. At experimental times of $0,7,14,21$ and 28 days, dentin chips were removed from the canals with sequential sterile low-speed round burs with increasing diameters of ISO sizes: 025, 027, 029, 031 and 033, respectively. Each bur removed approximately $0.1 \mathrm{~mm}$ of dentin around the canal. The powder dentin samples obtained with each bur were immediately collected in separate test tubes containing $3 \mathrm{ml}$ of freshly prepared BHI. Thereafter, $100 \mu \mathrm{L}$ from each test tube was cultured on blood agar. Growing colonies were counted and recorded as CFU.

Analysis of variance and covariance with repeated measures was used (ANOVA) to indicate differences between the experimental groups and the positive control. In addition, One-way ANOVA (Tukey's method) was used to indicate differences within each layer.

\section{Results}

The number of CFU obtained from five consecutive dentinal layers was presented in table 1 . The number of $\mathrm{CFU}$ in all three experimental groups was minimum after treatment. The positive control group showed viable bacteria at all experimental times, which indicated the efficiency of the method. In contrast, the negative control group showed no viable bacteria at all experimental times. At all five experimental periods, the Tetraclean group showed the most effective antibacterial action (P $<0.05$ ). Hypoclean group showed no bacterial growth after treatment. Furthermore, at days 7, 14, 21, and 28 demonstrated more effective antibacterial action than $5.25 \% \mathrm{NaOCl}$.

\section{Discussion}

Enterococcus faecalis is found in 4-40\% of primary endodontic infections (15). However, its frequency in persistent periradicular lesions has been shown to be nine times higher. Its prevalence in root-filled teeth with periradicular lesions using culturing and polymerase chain reaction (PCR) methods is $24-70 \%$ and $67-77 \%$, respectively (15). E. faecalis possesses several virulence factors. However, it relies more upon its ability to survive and persist as a pathogen in the root canals of teeth (16). Furthermore, its capacity to endure prolonged periods of starvation until an adequate nutritional supply becomes available has been demonstrated (16).

Considering the fact that current techniques of root canal instrumentation leave many areas of the root canal completely untouched by the instruments (17), an irrigation solution is required to aid in the debridement of the canals. For improvement of their efficacy, root canal irrigants the irrigants must be in contact with the dentin walls and debris (18). The intimacy of this contact depends on the wettability of the irrigant on solid dentin, and this property of the liquid is strictly correlated to its surface tension (18). The surface tension is defined as "the force between molecules that produces a tendency for the surface area of a liquid to decrease" (19). This force tends to limit the ability of the liquid to penetrate a capillary tube. Endodontic irrigants should have very low surface tension. The wettability of the solution governs the capability of its penetration both into the main and lateral canals, and into the dentinal tubules (20). By improving the wettability, an irrigant antimicrobial solution could increase its protein solvent capability and enable better activity in uninstrumented areas of root canal system (RCS) (20). In the present study a new modified $\mathrm{NaOCl}$ solution (Hypoclean) was tested for its residual antibacterial substantivity and penetration depth into dentinal tubules and was compared to Tetraclean and $5.25 \% \mathrm{NaOCl}$ for 28 days. The mean

Table 1. Mean of the CFU and the standard deviations of E. faecalis in the experimental groups.

\begin{tabular}{|l|c|c|c|c|c|}
\hline & Day 0 & Day 7 & Day 14 & Day 21 & Day 28 \\
\hline Tetraclean & $0.00 \pm 0.00$ & $0.00 \pm 0.00$ & $0.37 \pm 0.65$ & $6.68 \pm 2.59$ & $15.35 \pm 3.21$ \\
\hline Hypoclean & $0.00 \pm 0.00$ & $7.50 \pm 2.49$ & $18.00 \pm 2.71$ & $30.70 \pm 6.42$ & $48.30 \pm 5.41$ \\
\hline NaOCl & $0.31 \pm 0.58$ & $17.16 \pm 7.05$ & $34.40 \pm 8.79$ & $66.78 \pm 10.11$ & $95.25 \pm 5.61$ \\
\hline
\end{tabular}


numbers of CFU were statistically lower in Tetraclean compared with other solutions at all experimental periods, thus stressing the ability of Tetraclean to adsorb to hydroxyapatite with prolonged gradual release at therapeutic levels. The modified $\mathrm{NaOCl}$ solution showed more effective antibacterial activity than $5.25 \% \mathrm{NaOCl}$ at all experimental periods. In order to reduce surface tension, modified $\mathrm{NaOCl}$ solution contains two detergents. In preliminary test (data not published) the modified $\mathrm{NaOCl}$ solution showed the lowest value of surface tension $\left(30.0 \pm 0.8 \mathrm{~mJ} / \mathrm{m}^{2}\right)$ than $5.25 \% \mathrm{NaOCl}(49.0 \mathrm{~mJ} /$ $\mathrm{m}^{2}$ ) according with the Wilhelmy plate technique, using a Cahn DCA-322 Dynamic Contact Angle Analyzer (Gibertini Elettronica Novate (MI), Italy). Considering the fact modified $\mathrm{NaOCl}$ group displayed no bacterial growth at two first cultures, it can be concluded that it penetrated deeper into dentinal tubules than regular $5.25 \% \mathrm{NaOCl}$ solution. However, $\mathrm{NaOCl}$ even when is combined with a detergent, has little to no antibacterial substantivity, which is in agreement with the findings of other studies. The likely reason is that $\mathrm{NaOCl}$ has an antimicrobial effect as long as free chlorine is available in the solution (21). Due to its high surface tension (20), regular $\mathrm{NaOCl}$ cannot penetrate into deeper layers of dentin. Giardino et al. (14) demonstrated that the surface tension of Tetraclean was lower than MTAD and $\mathrm{NaOCl}$ that is in accordance to the findings of the present study. In a study to assess the antibacterial substantivity of $2.6 \% \mathrm{NaOCl}$, MTAD, and chlorhexidine, Mohammadi and Shahriari (12) found that the substantivity of MTAD was significantly greater than CHX and $\mathrm{NaOCl}$, which is in according to the present findings. In another study, Khademi et al. (13) found the antibacterial substantivity of $2.6 \% \mathrm{NaOCl}$ was significantly lesser than $2 \% \mathrm{CHX}$ and $100 \mathrm{mg} / \mathrm{ml}$ doxycycline. Giardino et al. (22) revealed that MTAD and Tetraclean induced the largest zone of microbial inhibition of E. faecalis cultured under both aerobic and anaerobic conditions, when compared with $\mathrm{NaOCl}$ which is in accordance to the findings of the present study.

Another thing concerning the substantivity of root canal irrigants is the time of dentin treatment to induce substantivity. There is a considerable debate in the literature regarding the time of dentin treatment to induce substantivity. Some works have demonstrated that only 5-10 min treatment with CHX induces substantivity (23-25). On the other hand, some studies have shown that dentin should be treated for one week to induce substantivity. Komorowski et al. (26) reported that for induction of substantivity, dentin should be treated with CHX for 7 days and 5 min treatment with CHX did not induce substantivity, which is in contrast to our findings. Lin et al. (27) attributed the limited antibacterial effect of CHX irrigation to absorb the medication to dentin during the first hour and stated that only after the saturation point after the first hour that the antibacterial capability of CHX increase with time.

In conclusion, under the conditions of the present study, the substantivity of Tetraclean was significantly higher than both Hypoclean and $\mathrm{NaOCl}$ solutions and retained in root canal dentin for at least 28 days.

\section{References}

References with links to Crossref - DOI

1. Kakehashi S, Stanley HR, Fitzgerald RJ. The effects of surgical exposures of Dental pulps in germ-free and conventional laboratory rats. Oral Surg Oral Med Oral Pathol. 1965;20:340-9.

2. Möller AJ, Fabricius L, Dahlén G, Ohman AE, Heyden G. Influence on periapical tissues of indigenous oral bacteria and necrotic pulp tissue in monkeys. Scand J Dent Res. 1981;89:475-84.

3. Sundqvist G. Ecology of the root canal flora. J Endod. 1992;18:42730 .

4. Mohammadi Z, Abbott PV. On the local applications of antibiotics and antibiotic-based agents in endodontics and dental traumatology. Int Endod J. 2009;42:555-67.

5. Peters OA, Laib A, Göhring TN, Barbakow F. Changes in root canal geometry after preparation assessed by high-resolution computed tomography. J Endod. 2001;27:1-6.

6. Byström A, Sundqvist G. Bacteriologic evaluation of the efficacy of mechanical root canal instrumentation in endodontic therapy. Scand J Dent Res. 1981;89:321-8.

7. Mohammadi Z, Farhad A, Tabrizizadeh M. One-visit versus multiple-visit endodontic therapy--a review. Int Dent J. 2006;56:289-93.

8. Haapasalo M, Orstavik D. In vitro infection and disinfection of dentinal tubules. J Dent Res. 1987;66:1375-9.

9. Byström A, Sundqvist G. Bacteriologic evaluation of the effect of 0.5 percent sodium hypochlorite in endodontic therapy. Oral Surg Oral Med Oral Pathol. 1983;55:307-12.

10. Hasselgren G, Olsson B, Cvek M. Effects of calcium hydroxide and sodium hypochlorite on the dissolution of necrotic porcine muscle tissue. J Endod. 1988;14:125-7.

11. Navarro-Escobar E, González-Rodríguez MP, Ferrer-Luque CM. Cytotoxic effects of two acid solutions and $2.5 \%$ sodium hypochlorite used in endodontic therapy. Med Oral Patol Oral Cir Bucal. 2010;15:e90-4.

12. Mohammadi Z, Shahriari S. Residual antibacterial activity of chlorhexidine and MTAD in human root dentin in vitro. J Oral Sci. 2008;50:63-7.

13. Khademi AA, Mohammadi Z, Havaee A. Evaluation of the antibacterial substantivity of several intra-canal agents. Aust Endod J. 2006;32:112-5.

14. Giardino L, Ambu E, Becce C, Rimondini L, Morra M. Surface tension comparison of four common root canal irrigants and two new irrigants containing antibiotic. J Endod. 2006;32:1091-3.

15. Stuart CH, Schwartz SA, Beeson TJ, Owatz CB. Enterococcus faecalis: its role in root canal treatment failure and current concepts in retreatment. J Endod. 2006;32:93-8.

16. Rôças IN, Siqueira JF Jr, Santos KR. Association of Enterococcus faecalis with different forms of periradicular diseases. J Endod. 2004;30:315-20.

17. Shabahang S, Pouresmail M, Torabinejad M. In vitro antimicrobial efficacy of MTAD and sodium hypochlorite. J Endod. 2003;29:450-2.

18. Pécora JD, Guimarães LF, Savioli RN. Surface tension of several drugs used in endodontics. Braz Dent J. 1992;2:123-7.

19. Taşman F, Cehreli ZC, Oğan C, Etikan I. Surface tension of root canal irrigants. J Endod. 2000;26:586-7.

20. Cameron JA. The effect of a fluorocarbon surfactant on the surface tension of the endodontic irrigant, sodium hypochlorite. A preliminary report. Aust Dent J. 1986;31:364-8.

21. Zehnder M. Root canal irrigants. J Endod. 2006;32:389-98.

22. Giardino L, Savoldi E, Ambu E, Rimondini R, Palezona A, Debbia EA. Antimicrobial effect of MTAD, Tetraclean, Cloreximid, and 
sodium hypochlorite on three common endodontic pathogens. Indian J Dent Res. 2009;20:391.

23. Rosenthal S, Spångberg L, Safavi K. Chlorhexidine substantivity in root canal dentin. Oral Surg Oral Med Oral Pathol Oral Radiol Endod. 2004;98:488-92.

24. White RR, Hays GL, Janer LR. Residual antimicrobial activity after canal irrigation with chlorhexidine. J Endod. 1997;23:229-31.

25. Leonardo MR, Tanomaru Filho M, Silva LA, Nelson Filho P, Bonifácio KC, Ito IY. In vivo antimicrobial activity of $2 \%$ chlorhexidine used as a root canal irrigating solution. J Endod. 1999;25:167-71.

26. Komorowski R, Grad H, Wu XY, Friedman S. Antimicrobial substantivity of chlorhexidine-treated bovine root dentin. J Endod. 2000;26:315-7.

27. Lin S, Zuckerman O, Weiss EI, Mazor Y, Fuss Z. Antibacterial efficacy of a new chlorhexidine slow release device to disinfect dentinal tubules. J Endod. 2003;29:416-8. 